\title{
Effects of Porosity and Permeability on Invasion Depth During Drilling Mud-filtrate Invading into a Reservoir Dynamically
}

\author{
Jianhua Zhang \\ Science College, Xi'an Shiyou University, Xi'an, 710065, China \\ jhzhang@xsyu.edu.cn
}

Keywords: Invasion; Depth; Time; Porosity; Permeability

\begin{abstract}
The drilling mud-filtrate invades into a reservoir is a dynamical process after a formation was opened in oil exploration. Since the invasion profiles of formation resistivity vary with time, the invasion depth is related to time. The fluid flow equations were used to calculate the invasion profiles and invasion depth. The present dynamic invasion model generated the time-dependent formation resistivity profiles and invasion depth. The effects of two main parameters, porosity and permeability, for a permeable and porous formation were studied. The invasion depth increases with the growing permeability and decreasing porosity.
\end{abstract}

\section{Introduction}

In petroleum exploration, mud was used while drilling. The mud filtrate invades into permeable and porous formations; thus invaded zone that was consisted of mud filtrate mainly was formed [1]. The characteristic of invaded zone is very different from the original formation. The invasion zone has strong affects on resistivity logging [2], which is the primary method to estimate the resistivity of original formations and to evaluate reservoirs.

Usually, the invasion description was conventional step-invasion model that presumes there was a sharply resistivity profile at the boundary of invaded zone and uninvaded formation [3]. However, a realistic invasion process is related to time. At the beginning of opening a formation, the invasion rate of mud filtrate is fast. With the lapse of time, mud cake is built at the wall of borehole; then the invasion rate becomes slowly. The dynamic invasion process and its effect on well logging have been investigated internationally [4-8].

The displacement of moveable hydrocarbon in a formation by filtrate is a percolation process. On one hand, the formation- and fluid-related parameters do not vary in a step invasion style; on the other hand, the invasion process is dynamic. The fluid flowing theory was used to solve the dynamic invasion process. Comparing the dynamic model with conventional step-invasion version, the time-dependent invasion profiles and invasion depth are helpful to understand the behaviors of invasion process and to evaluate reservoirs.

\section{Dynamic Invansion Equations}

Mud filtrate invades into a formation radially and displaces the native fluids in porous volumes. The displacement between filtrate and hydrocarbon is immiscible. During drilling, mud filtrate pours into the formation under the pressure differential between borehole and formation after a bed was reached. The invasion process is related to formation permeability, formation porosity, original saturation, native-water salinity and mud-filtrate salinity, viscosity of fluids, capillary pressure, and so on. The shape of invasion profiles will change at various time stages. They can be calculated from fluid flow equations $[6,7]$ :

$$
\nabla \cdot\left(\frac{\rho_{w} k k_{r w}}{\mu_{w}} \nabla P_{w}\right)+q_{w}=\frac{\partial}{\partial t}\left(\varphi \rho_{w} S_{w}\right)
$$




$$
\nabla \cdot\left(\frac{\rho_{o} k k_{r o}}{\mu_{o}} \nabla P_{o}\right)+q_{o}=\frac{\partial}{\partial t}\left(\varphi \rho_{o} S_{o}\right)
$$

Where, $k$ is the absolute permeability of the formation, $\varphi$ the formation porosity, $t$ the invasion time, and $k_{r w}, \mu_{w}, \rho_{w}, S_{w}, P_{w}, q_{w}$ are the relative permeability, viscosity, density, saturation, pressure, and the mass flow rate per unit of rock volume for water phase, respectively; and $k_{r o}, \mu_{o}, \rho_{o}, S_{o}, P_{o}$, $q_{o}$ are parameters for oil phase.

The sum of oil saturation $S_{o}$ and water saturation $S_{w}$ must be unity because the pores in a formation are filled with fluids completely, $S_{o}+S_{w}=1$. From Eqs.(1) (2), the pressures $P_{w}(r, t)$ and $P_{o}(r, t)$ and saturations $S_{w}(r, t)$ and $S_{o}(r, t)$ can be obtained as functions of time $t$ and radial distance $r$.

Since salinity between mud filtrate and formation water is usually different, the mixing of mud filtrate with native water causes the variation of salinity distribution with time during invasion. The variation of water salinity is generated from dispersion equation for the radial displacement process:

$$
\frac{1}{r} \frac{\partial}{\partial r}\left(\frac{r k k_{r w} C_{w}}{\mu_{w}} \frac{\partial P_{w}}{\partial r}\right)+q_{w} C_{m f}=\frac{\partial\left(\varphi S_{w} C_{w}\right)}{\partial t}
$$

Where, $C_{w}$ and $C_{m f}$ are water salinity and mud-filtrate salinity respectively; $r_{b}$ is the radius of borehole. Petrophysics theory gives the formation water resistivity, $R_{w}(r, t)$, and formation resistivity, $R_{f}(r, t)$, as functions of time $t$ and radial coordinate $r$.

$$
\begin{aligned}
& R_{w}(r, t)=\left(0.0123+\frac{3647.5}{C_{w}^{0.955}(r, t)}\right) \cdot \frac{82}{1.8 T+39} \\
& R_{f}(r, t)=\frac{a R_{w}(r, t)}{S_{w}^{n}(r, t) \varphi^{m}}
\end{aligned}
$$

Where $a, m$, and $n$ are constants.

\section{Time-dependent Invasion Depth}

A synthetic formation model was constructed to illustrate the behavior of dynamic invasion with the following formation parameters: $k=0.3 \mu \mathrm{m}^{2}, \varphi=0.12$, initial formation-water saturation $S_{w}=0.5$. $C_{m f}$ $=80000 \mathrm{mg} / \mathrm{L}$ and $C_{w}=10000 \mathrm{mg} / \mathrm{L} ; T=80^{\circ} \mathrm{C}, \mu_{w}=2.83 \times 10^{-9} \mathrm{~Pa} \cdot \mathrm{s}, \mu_{o}=6.0 \times 10^{-9} \mathrm{~Pa} \cdot \mathrm{s}, \rho_{w}=1 \mathrm{~g} / \mathrm{cm}^{3}$, and $\rho_{o}=0.7 \mathrm{~g} / \mathrm{cm}^{3}$. The pressure difference between borehole and original reservoir $\triangle P=4 \mathrm{MPa}$. The constants in Eq.(8) were: $a=1, m=2$, and $n=2$. The diameter of well was $20.32 \mathrm{~cm}$ ( 8 inch).

Solving Eqs.(1) (2), saturation can be obtained. Fig.1(a) show the radial invasion profile of water saturation at various time stages $(0,3,9,26$ and 57 days respectively) after the bed was reached. The horizontal axis denotes radial coordinate. The vertical line of $t=0$ corresponded the radial position of well radius. When mud filtrate invades into a formation, usually a high water saturation zone is formed in the vicinity of borehole. Under the driving force of pressure difference between borehole and original formation, the mud filtrate moves to the formation gradually. At the beginning of bit penetration, mud poured into formation rapidly and mud cake is built up within a short time stage [9]. The saturation profile changed and move into formation rapidly. With the extension of invading geometry area and the building of mud cake, the invasion rate decreases with time. The invasion rate and the saturation profile movement decreased gradually.

The salinity difference between mud filtrate and native water caused the salinity profile. It can be calculated from Eq.(3). Then the formation resistivity was calculated according to Eq.(4) and Eq.(5). Fig.1(b) drew the calculated radial profiles of formation resistivity at five time stages. Since high salinity results low resistivity, in the neighbor of wellbore, the pores in formation were filled with low-resistivity mud filtrate; hence the formation resistivity was low. With the lapse of invasion, the 
low-resistivity mud filtrate pored into the formation, hence the $R_{f}$ profile changed with time. There is not a sharp boundary between invaded zone and uninvaded formation.

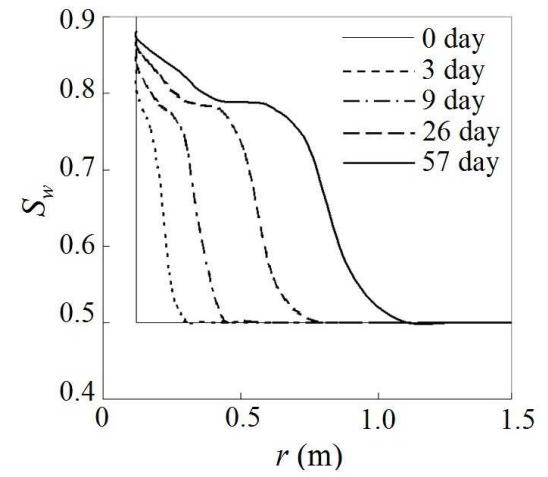

(a)

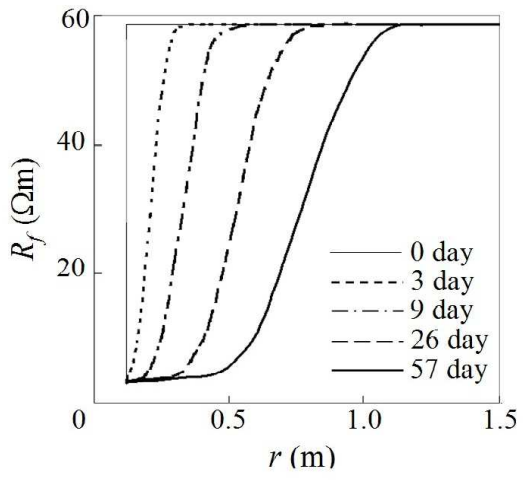

(b)

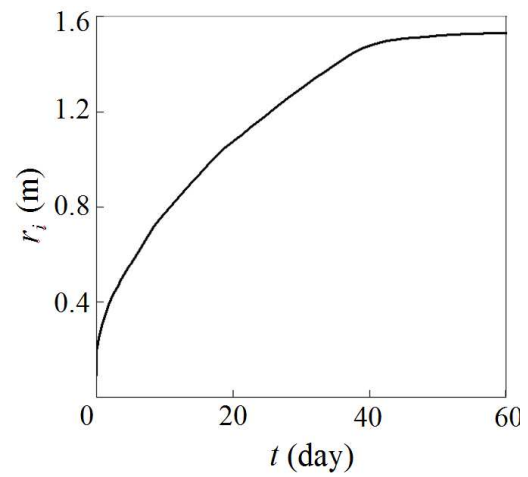

(c)

Figure 1. Behaviors of dynamic invasion: (a) radial profile of water saturation;

(b) radial profile of formation resistivity; (c) various invasion depth $r_{i}$ with time $t$.

The invasion depth was the distance from the borehole to the boundary of invasion zone and undisturbed formation [10]. Since the profile of formation resistivity migrated into the deep formation with time, the invasion depth $r_{i}$ varies with the invasion time $t$ as well. Fig.1(c) illustrated the behavior. At the beginning of drilling, mud filtrate poured into formation rapidly with a high invasion rate, so that the invasion depth increased with time rapidly, see Fig.1(c). With the extending of invasion geometry and the building of mud cake at the wall of borehole, the invasion profile moves into the formation with a reduced rate. After the mud cake on the borehole was formed, the penetration of mud filtrate invasion tend to stable, the increment of invasion depth became slowly.

\section{The Effects of Porosity and Permeability}

The invasion of mud filtrate into a reservoir is affected by parameters related to formation and fluids. Porosity $\varphi$ and permeability $k$ are two important parameters to address a formation. The accumulations in pore spaces of reservoir rocks were importance for the oil and gas production. Porosity is the pore volume per unit volume of formation; it is the fraction of the total volume of a sample that is occupied by pores or voids. Permeability is a measure of the ease with which fluids can flow through a formation.

Fig.2(a) show the effects of permeability $k$ on invasion depth $r_{i}$ at various invasion time $t$. The main input data used in the calculation were: $S_{w}=0.5, C_{m f}=280000 \mathrm{mg} / \mathrm{L}, C_{w}=170000 \mathrm{mg} / \mathrm{L}, T=80^{\circ} \mathrm{C}$, $a=3.75, m=1.8$, and $n=2$. For a low porous bed, $\varphi=0.05$, the invasion depths varied with invasion time were drawn in Fig.2(a) for absolute permeability $k=0.01,0.005$, and $0.001 \mu^{2}$ respectively. With the lapse of invasion time, the invasion front moved into the formation and the invasion depth increased. In addition, great value of permeability $k$ means good flow ability; hence the greater the permeability was, the deeper the invasion depth became.

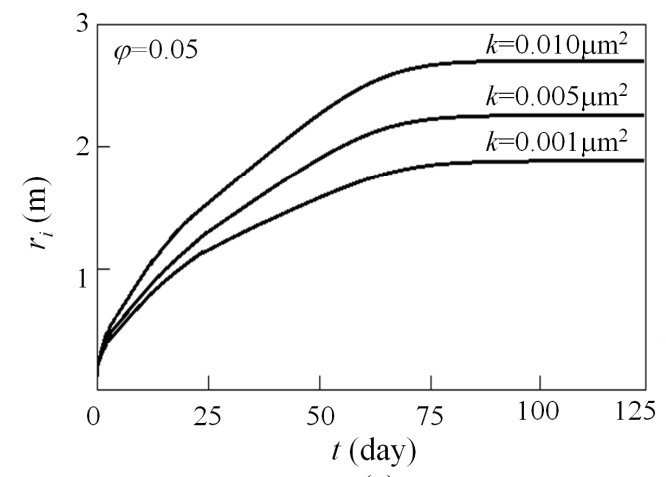

(a)

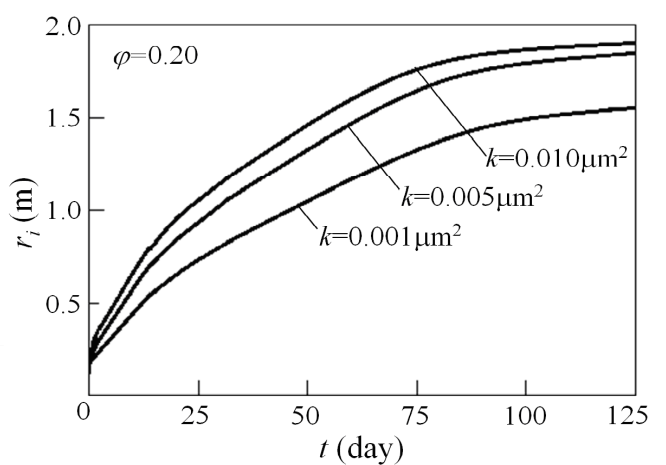

(b)

Figure 2. Effects of permeability and porosity on invasion depth $r_{i}$ for (a) $\varphi=0.05$ and (b) $\varphi=0.20$ 
For a high porous formation with porosity $\varphi=0.20$, the volume in pore was large. More mud filtrate was needed to replace the native fluids (water, oil or gas); thus, the invasion rate decreased. For example, when invasion time $t=25 \mathrm{day}$, for low porosity $\varphi=0.05$, the invasion depths were 1.16 , 1.31 , and $1.56 \mathrm{~m}$ for permeability $k=0.01,0.005$, and $0.001 \mu \mathrm{m}^{2}$ respectively, as shown in Fig.2(b). Whereas the invasion depths were only $0.73,0.91$, and $1.08 \mathrm{~m}$ for same permeability values when mud invasion a high porosity formation $(\varphi=0.2$, as shown in Fig.2(b)). In addition, for the lowporosity formation, invasion depths reached its stable values at early time ( $t=75$ day, for Fig.2(a)). For the high-porosity formation, invasion depths reached its stable values at later time $(t>125$ day, for Fig.2(b)).

\section{Conclusions}

Invasion process is related to formation and fluid parameters. Both porosity and permeability are important parameters to describe the character of a formation. They are also influence the invasion process heavily.

High value of permeability $k$ means good flow ability; hence the greater the permeability was, the deeper the invasion depth became.

High porosity means that the volume in pore was large. More mud filtrate was needed to replace the native fluids (water, oil or gas); thus, the invasion rate decreased.

\section{References}

[1] A. Y. Windarto, Gunawan, P. Sukarno, E. Soewono, Modeling of mud filtrate invasion and damage zone formation, J. Pet. Sci. Eng., Vol.77(2011)No.3-4, p.359-364

[2] S. Davydycheva, Two triaxial induction tools: Sensitivity to radial invasion profile, Geophysical Prospecting, Vol.59(2011)No.2, p.323-340

[3] M. S. Bittar, P. F. Rodney, W. E. Hendricks, Invasion profiling with a multiple-depth-ofinvestigation electromagnetic-wave resistivity sensor, SPE Production and Facilities, Vol.12(1977)No.1, p.10-15

[4] D. P. Tobola, and S. A. Holditch, Determination of reservoir permeability from repeated induction logging, SPE Formation Evaluation, (1991)March, p.20-26

[5] C. Y. Yao and S. A. Holditch, Reservoir permeability estimation from time-lapse log data, SPE Formation Evaluation, (1996) June, p.69-74

[6] J. H. Zhang, Q. Hu and Z. H. Liu, Estimation of true formation resistivity and water saturation with a time-lapse induction logging method, The Log Analyst, Vol.40(1999)No.2, p.138-148

[7] Z. H. Liu, J. Oyang, and J. H. Zhang, Dynamic Dual-Laterolog Responses: Model and Field Applications in the Bohai Gulf of China, J. Pet. Sci. Eng., Vol.23(1999)No.1-2, p.1-11.

[8] Akinsete, O.Oluwatoyin and Adekoya, Effects of mud filtrate invasion on well $\log$ measurements, The SPE Nigeria Annual International Conference \& Exhibition (Lagos, Nigeria, 2-4 August, 2016)

[9] A. N. Berntsen, A. S. Robbes, P. R. Cerasi, C. H. Van Der Zwaag, Laboratory investigation of brine diffusion through oil-based mud filter cakes, SPE International Symposium on Formation Damage Control, SPE 128027, (2010) p.731-740

[10]K. Ling, H. Zhang, Z. Shen, A. Ghalambor, G. Han, J. He and P. Peng, A new approach to estimate invasion radius of water-based-drilling-fluid filtrate to evaluate formation damage caused by overbalanced drilling, SPE Drill. Complet, Vol.30(2015), p.27-37 